\title{
7 Classification of illnesses in the Hippocratic Corpus
}

\author{
Elizabeth Craik
}

In the absence of the scans, tests and procedures that are routine and familiar today, with no awareness of bacterial and viral effects and without information of infection and contagion, the ancient physician had to rely on skills acquired from past experience and more immediately on the evidence of his senses - sight, hearing, touch, smell and, occasionally, taste - to make judgements about the identity and character of the different illnesses he encountered. This simple pragmatic combination of past experience and present observation was supplemented to different degrees by various theoretical suppositions about the nature and function of the body in health and illness and, especially, of the fluids observed - not always incorrectly - to be important in its physiological working and pathological breakdown. Whereas observations are, inevitably, liable to be more or less homogeneous in character and so lead to common conclusions, theories tend to be heterogeneous in their starting assumptions, as well as in their degree of sophistication, and so may lead to a range of different views. Many of these theories, as we find them recorded in our texts, are evidently traditional and orthodox, while a few are seemingly more individual and original.

The Hippocratic Corpus is immense, comprising some 60 to 70 works, and immensely complex: not only authorship but also their form and content are extremely varied. ${ }^{1}$ The association between the Corpus and the historical Hippocrates, certainly exaggerated by past generations of physicians and scholars, is now seen to be at best nebulous and perhaps in the last resort even illusory. In form, the Corpus contains a wide assemblage of material, ranging from polished treatises to disorganised notes, while in content it embraces topics in anatomy, physiology, pathology, surgery and gynaecology as well as in dietetics and medical ethics. Some works are relatively narrow in scope and display a degree of medical specialisation, while others are very wide-ranging and provide general guidance to the practitioner, either in the form of a complete vademecum, or as a series of aphoristic nostrums. This diversity is indisputable and fully recognised by modern scholarly consensus. However, at the same time, it might seem reasonable to look for some underlying unity in a collection of works of common medical content, all nominally associated with a historical figure of the fifth century $\mathrm{BCE}$. And one might expect there to be some significant coincidences in a collection of works that have a common origin in a relatively restricted geographical 
and ethnological setting (the Greek world, including regions to the east, west and south of the Greek peninsula extending to the Black Sea region, Sicily and Libya) and a limited time frame (essentially sixth to fourth centuries BCE, though there are a few later outliers).

In this chapter it will be seen that, despite general unity in overall ideas about diseases and disease classification, there is considerable diversity in presentation and emphasis. This examination and discussion of Hippocratic ideas ranges widely over miscellaneous examples drawn from the entire corpus. While naturally - most attention is paid to those works which are devoted primarily to nosology, pathology and therapy - namely On Regimen in Acute Diseases, On Affections, On Internal Affections, On Diseases 1, On Diseases 2, On Diseases 3 (Acut., Aff., Int., Morb. 1, Morb. 2, Morb. 3) - attention is paid also to a range of works devoted to management of cases, especially Epidemics 1-7, Prognostic and Prorrhetic 2 (Epid. 1-7, Prog., Prorrh. 2); and to some works of surgical content, such as On Sight, On Fistulas and On Haemorrhoids (Vid. Ac., Fist. and Haem.); as well as to some more wide-ranging works, such as Aphorisms (Aph.) and Places in Man (Loc. Hom.). It may be that the diversity and fluidity found to characterise the surviving schemes of classification is related to the nature of Hippocratic writing, itself fundamentally diverse and essentially fluid. It is evident that different circles or groups of physicians coexisted, some working in close cooperation but others competing in bitter rivalry: there were different patterns of discourse, different levels of knowledge and so, as a consequence, different concepts and different views.

Many works are clearly multi-authored and as such can properly be described as compilations rather than compositions. This kind of writing surely militates against precise and schematic classification, such as an individual thinker writing an organised treatise might impose. The gynaecological works in particular comprise a loose amalgam of material, with accretions apparently from different eras. The Epidemics (Epid.) contain records clearly assembled and stitched together by different hands at different times, datable to a period of some six decades, from late fifth to mid-fourth century. ${ }^{2}$ It appears that a similar complex history of successive redactions marked an important earlier work, known to us by name but now lost, Knidian Opinions. The process of composition and circulation of this hazy work cannot be reconstructed, but that there were several initial writers and several subsequent revisers can be deduced from scanty and allusive Hippocratic references in On Regimen in Acute Diseases (Acut.). It seems too that Knidian Opinions was schematic and aphoristic in layout and character.

It is generally agreed that most, if not all, of the nosological works preserved in the Hippocratic Corpus drew material from the lost Knidian Opinions. However, even where there may be some such common source, various presentations have ensued, and the resultant categorisations, though all seemingly derivative, are by no means homogeneous. Authors do classify diseases, but there is no general agreement on a system of classification, or indeed on the number and nature of the diseases to be included. Accordingly, while we might expect to find the highest degree of unanimity in those works where diseases are listed sequentially - $O n$ 
Internal Affections, On Diseases 1, On Diseases 2, On Diseases 3 (Int., Morb. 1, Morb. 2, Morb. 3) - there are markedly different patterns of arrangement with different types of emphasis in these nosological presentations. ${ }^{3}$ That particular diseases do recur in the lists recorded there and that attention is regularly devoted to the same common elements - aetiology or cause, pathology or symptoms, prognosis or outlook and therapy or treatment - is unmistakeable, but there are salient differences, and there is certainly no single pattern of classification. It may be remarked, however, that the question of aetiology - causation - tends to predominate. There is general unanimity on the importance of understanding the origin or cause, especially the ultimate underlying cause, of diseases. In such writing, the underlying cause was often designated prophasis. (This term was adopted from medical writing and adapted to regular usage; thus, Thucydides famously applied the term prophasis to the root cause of the Peloponnesian War.) However, the fluidity apparent in many respects is apparent here, too: some authors use the alternative expression aphormai or simply aition in the same sense as the more 'technical' term prophasis. Prognostic considerations too are generally prominent.

We ought to observe at this point that in perception of disease phenomena, Greek medicine has no precise notion of 'disease' as a category. The word most frequently used of disease or illness is nosos, as in the series On Diseases 1, 2, 3, 4 (Morb. 1, Morb. 2, Morb. 3, Morb. 4); the related, more concrete, nosema is used also, as are such terms as ponos 'trouble' and the rather general pathos 'affection', seen in On Affections and in On Internal Affections (Aff. and Int.). However, in regular discussion, many situations designated in these ways and apparently regarded as identifiable diseases would be regarded in modern terms as conditions, syndromes or simply symptoms rather than as constituting illnesses or diseases in themselves. One striking example is that fever (in modern terms viewed as a symptom) was commonly regarded as a disease and an important one at that. In addition, fever was - understandably - widely viewed as a core element in all disease, especially in acute diseases. An entire section of the Aphorisms, a collection of immense influence in the long Hippocratic tradition, is devoted to detailing prognostic signs determining outcomes in aspects of fevers (Aph. 4). For a fevered or feverish state, many different terms were used: the terms pyretos, pyr, kausos and therme coexist. To some extent divergences in usage are due simply to authorial preference and practice, but at the same time, certain authors differentiate carefully between types of fever. Of course, any judgement of the degree of fever was subjective, not based on precise measurement of any kind. Thus, in On Regimen in Acute Diseases (Acut. B 1, 7-8), distinctions are drawn between types of kausos and also in the nuances of usage in pyretos and kausos. A further term, epialos, is used of a particular, suddenly appearing, recurrent - probably malarial - fever in On Airs, Waters and Places (Aer.) and elsewhere. Malaria, though neither recognised nor named as one particular disease, was undoubtedly prevalent in Greek lands. ${ }^{4}$

Like fever, ikteros 'jaundice' was commonly regarded as an illness in its own right, though different types of jaundice were distinguished as having different features and different causes; and like fever, jaundice regularly presents in 
malaria. A connection between these two conditions, fever and jaundice, is perceptively noted in On Regimen in Acute Diseases (Acut.). In the same way, coma was recorded as if an independent rather than contingent circumstance; and, also, hydrops 'dropsy', the presence of unwanted bodily fluid, now known to occur as a result of many different conditions or for miscellaneous reasons, was itself viewed as an independent disease which might take different forms. Similarly, the term spasmos 'spasm' or 'convulsion' was utilised as a term of disease to describe any kind of paroxysmal motion; it is sometimes found in conjunction with tetanos. The latter term is sometimes used with a similar connotation to modern tetanus, but sometimes with much less precision. Finally, problems affecting the hips, described variously as ischias and kedmata, seem to belong in the category of chronic joint conditions in orthopaedics rather than to constitute diseases or illnesses.

In the lists of diseases current in the nosological works, there are two main systems of ordering. Most Hippocratic authors list diseases according to the place in the body affected, the arrangement beginning with the head and proceeding to the lower parts of the body: this arrangement is broadly topographical (based on bodily region) rather than specifically anatomical (based on a particular organ or bodily part). The usual formula introducing a particular disease for discussion is by a descriptive conditional or temporal clause: 'If such and such happens ...' or 'When such and such happens ...'. The alternative arrangement favoured by some writers is to introduce the names of diseases to be discussed in an ordered sequence. In the latter type of grouping there is much ambiguity, as some diseases are thought to have several variations, most often itemised in a numbered list but occasionally, as in On Regimen in Acute Diseases (Acut.), distinguished by eidos, genos or phusis (words indicative of sort, grouping or character of diseases) as presenting in different types. In this, the listing of characteristics tends to take precedence over firm nomenclature. Some authors, like the writer of Prognostic (Prog.), distance themselves from the practice of assigning names, but nevertheless fall into similar habits in nomenclature. A few treatises utilise both methods, using at some points the descriptive method and at others the method of listing. Nomenclature in general tends to the rudimentary. Prognosis took precedence over diagnosis and there was little notion of differential diagnosis. Speculation on the interrelation of diseases was common and a complex series of connections might be postulated to explain apparent mutation from one disease to another.

Nosological nomenclature is in many cases simply descriptive. This is seen in a wide range of names, such as phthisis applied to a wasting disease; staphyle 'grape' used of a disease in which the swollen uvula looked grape-like; kynanche (kynanchos, synanche, synanchos), applied to a disease apparently taking its name from the choking sensation that typifies it; eileoi, named from a characteristic twisting or cramping sensation, and similarly bletos, indicating that the sufferer has been suddenly 'struck', as in our term 'stroke'. Some names are more colourful: the 'sacred disease' is so called because of its strange and seemingly supernatural manifestations. Most typically, disease names are associated with the place in the body affected: peripleumonie and pleuritis are chest diseases affecting the lung 
(pleumon); cholera is a disease arising from digestive bile (chole). That authors commonly remark on the practice of naming - 'they call this disease . . ' - is an instance of the fluidity already remarked. It is a significant aspect of this general fluidity that, as noted, many diseases were recognised to have a variety of manifestations with a tendency for one disease to mutate into another. And such terms as parakynanche, indicative of a disease like, but not identical with, regular kynanche, indicate a cautious awareness of the dangers inherent in the naming of complex conditions. We too must be cautious and aware of the dangers inherent in retrospective diagnosis. ${ }^{5}$

Instances of disease classification are on the whole simple. One obvious case is the demarcation of obstetrics and gynaecology from all other areas of medicine. It is explicitly observed, both initially and subsequently, in On Diseases of Women (Mul.) that particular constitutional makeup and particular medical needs are peculiar to women. A remarkably large proportion - in volume about a third of the corpus is devoted exclusively to gynaecological topics. ${ }^{6}$ In this, much attention is devoted to means of enhancing fertility, ensuring conception and securing safe childbirth. Explicit attention is paid to gynaecological questions in some other texts in addition to these works: typically, some gynaecological material suggested by the main content and viewed as relevant is loosely appended to the body of a treatise, as in On Places in Man, in On Glands and in On Fistulas, On Haemorrhoids (Loc. Hom., Gland. and Fist., Haem.). Gynaecology features largely in a section of Aphorisms (Aph. 5) and intermittently at many points in Epidemics (Epid.).

A distinction is commonly made between problems occasioned by external and internal causes. This distinction is clear in such cases as the trauma sustained in a fall, or occasioned by a war wound, but does break down in more sophisticated analysis, as causes apparently external may also be, or become, internal: for instance the heat of the sun may be thought to activate an excess of heat in the body. External causes feature especially in the surgical works and scarcely require explicit identification. Accidents in gymnasium and palaestra were everyday events and casualties wounded in warfare characterised by hand-to-hand combat were inevitably numerous: such eventualities of peace-time are treated in On Fractures and On Joints and of war-time treated in On Head Wounds (Fract., Artic. and $V C$ ). In addition, many cases in Epidemics relate to a wide range of domestic or other accidents, some trivial and transient, some serious and fatal. The short but insightful treatise On Diseases 1 (Morb. 1) begins by presenting different views of disease causation, seen to be important in schemes of classification. In this, external and internal causes are stressed at the outset.

Interest in a distinction between external and internal conditions is not refined but relates almost exclusively to theories of disease causation. One work, On the Art (Art.), offers a classification to the effect that diseases may be either clear and manifest (external) or unclear and hidden (internal). But this work, which evidently owes much to current sophistic thought, belongs in a world of intellectual speculation rather than of medical practice and so the distinction is a purely theoretical one. Although doctors must have been aware of potential treatments 
for internal conditions from contemporary veterinary medicine, there were surely ineluctable diagnostic problems in regular practice. It is certain that internal surgery was not extensively attempted. That the conditions of haemorrhoids and fistulas and with them that of genital warts - all externally visible, with the aid of a mirror - were well understood, is evident from the surgical works on these subjects (Haem., Fist.). However, internal surgical excision such as that for 'stone' seems to be proscribed in a passage of the celebrated Oath (Iusj.), though interpretation is here somewhat uncertain. Ophthalmology was perhaps seen as 'external': much attention was paid throughout antiquity to diseases of the eye, and considerable detail about surgical expedients can be seen in the Hippocratic On Sight (Vid. Ac.).

A distinction less obvious today, but one recurrent in many Hippocratic texts, is that between 'acute' and non-acute diseases. This is seen most patently in the important treatise On Regimen in Acute Diseases (Acut.), famous for its prescription of barley concoctions. Foremost among acute diseases are serious conditions affecting the lung such as peripneumonie, similar though not identical to modern pneumonia; but a range of other febrile conditions appears also. The author of On Diseases 1 (Morb. 1) refines the distinction between chronic and acute into a framework of diseases that are (invariably) fatal, that may (sometimes) be fatal and that are not (that is, are rarely if ever) fatal. The general distinction made between chronic and acute conditions may, in practical terms, have conditioned conduct on the part of the sick person. Whereas it was natural to have immediate recourse to a recognised physician when the situation was evidently acute and a disease imminently life-threatening, those suffering from chronic, rather than acute, complaints might go first to a shrine of Asclepios or another god of healing in hope of a cure. But there is no indication of such an alternative curative strategy in medical texts, and the theory that disease might have a divine causation is alien to Hippocratic thought.

A common criterion in disease categorisation is the topographical. As noted, authors of nosological works regularly describe diseases in a head-to-toe arrangement. Closely allied with this narrative is the prevailing orthodoxy that downward flux from the head occasioned disease. The causes of flux and the nature of fluids in flux, as regularly perceived or postulated, are significant variants in Greek medical thought. The consensus view that the sites of flux determine the nature of disease is regularly implicit rather than detailed explicitly. However, in $O n$ Places in Man (Loc. Hom.), much space is given to a careful listing of the effects of flux to numbered locations in the body: nose, ears, eyes, chest, belly, back and hips. A very similar sequence occurs in On Glands (Gland.) and some of the same elements occur, with slight variations (such as flux to throat, not to chest) in $O n$ Ancient Medicine $(V M)$. It is not difficult to categorise diseases centred on these bodily locations, but in our texts the stress is primarily on their supposed common aetiologies. Chest diseases are a manifestly coherent group, largely coincident with the 'acute' diseases of On Regimen in Acute Diseases (Acut.); the most important are pleuritis, peripleumonie and kausos, and it is clear from many texts that these are believed to display a complex pattern of interconnections and mutations, on which there is much debate but little agreement. 
We cannot go far in study of disease aetiology without regard to the nature and behaviour of bodily fluids, or 'humours'. Views of humoral motion or fixation, humoral location (whether appropriate or inappropriate) and humoral interaction to mutual benefit or mutation to incipient detriment are all crucial determinants of theories about disease development. Aetiology is an important criterion and it is agreed that the humours - especially bile and phlegm - are fundamental in disease pathology. Thus, the surgical works On Fistulas and On Haemorrhoids (Fist. and Haem.) place emphasis on bile and phlegm as precipitating causes. But consensus ends there: differences in presentation of bile and phlegm are legion. It is important to recognise that, contrary to popular belief, there was no canonical humoral theory in Hippocratic texts. In some works, the term 'humours' is applied to many different bodily fluids, as in On Humours (Hum.); in some works apparently concerned with humoral theory, the term 'humours' is not used at all, as in On the Nature of Man (Nat. Hom.). The humours are at times linked specifically with pathological abnormality, at times regarded as components in bodily makeup in health as well as in sickness. In some works, including On Diseases 4 (Morb. 4), this innate bodily material is thought to be linked with ingested food and drink. Thus, the notion that individuals differ in constitutions, some bilious and some phlegmatic, is widespread, as seen in On Affections, On the Sacred Disease, On Airs, Waters and Places (Aff., Morb. Sacr., Aer.) and also in the gynaecological works.

Even in works where the existence of four humours is specified, these are not always the same four. The best-known formulation - widely disseminated because it was adopted and promulgated by Galen - is that found in On the Nature of Man (Nat. Hom.): blood, phlegm, yellow bile and black bile feature as the four humoral elements. But in On Diseases 4 (Morb. 4), we find a different formulation: blood, phlegm, bile and water feature as the significant four. At first sight, variation in causative humoral effect might seem to be a possible indicator to classify diseases. However, in one treatise, clearly original in conception, the single cause of all disease is said to be 'wind' or 'air', On Winds (Flat.). Further, in many works where humoral aetiology is postulated, the cause is said to be bile and/or phlegm: the two humours are more often loosely linked than clearly opposed. There is persistent variation also in the detailed presentation of humoral character and humoral characteristics. Phlegm may be envisaged as hot and dry or as cold and moist; bile is subject to similar variation. Phlegm is most often thought to be white; bile is regularly yellow or reddish but may manifest itself as leaden or pale in colour. The most common pattern is to associate phlegm with cold and bile with heat; from these associations, it is natural to regard phlegm as a condition typical of winter and bile as typical of summer; phlegm is allied with colds, chills and chest problems while bile is allied with digestive upsets. Seasonal classification is a common expedient and in conjunction with this, environmental significance is regularly noted. It can readily be seen that the realities of the disease pattern in the Greek world are reflected in the rudimentary schemes of classification known to us. In hot Mediterranean summers, digestive upsets arising from food contamination were liable to occur; in the colder and wetter winters, chest disease was likely to be prevalent. In the autumn, malarial disease peaked. 
That different environmental and climatic conditions prevailing in different regions have a crucial effect in determining the health of their different inhabitants is, famously, argued in On Airs, Waters and Places (Aer.). The long treatise On Regimen (Vict.) stresses at the outset the impact on the individual of internal constitutional factors such as his/her age and of external environmental factors such as seasonal change. In Epidemics (Epid.), descriptions of local 'constitutions' are embedded; these incorporate salient climatic characteristics, seen to influence the health of both community and individual. Similar ideas are implicit in many other works. It may be that observation of a different disease pattern in summer (rather too hot and dry) and winter (rather too cold and wet) had a profound influence on Greek theories of disease aetiology, giving rise to theories of the significance of excess in disease causation. Perhaps these simple observations underlie the common view that excess of some kind - most specially an excess involving heat, or cold, or moisture, or dryness - affecting the body, or some part of it, is an internal cause or precipitating circumstance of disease. Personal excess, such as overindulgence in food, drink or sex, was commonly viewed as a cause also. Similarly, excess of exertion, such as that due to vigorous physical exercise or strenuous travel, as a cause of extreme fatigue was regarded as a predisposing factor.

What is the reason for disease classification? Surely it is primarily practical, to assist physicians in identifying problems presented to them. However, in practical terms, Hippocratic doctors are concerned not so much with diagnosis as with prognosis and with therapeutic strategy. And theoretical considerations are often paramount, as seen in the common stress on disease aetiology. The fundamental distinction between classification and semantics - understanding the nature of different diseases (including such features as causes, symptoms, therapy and predicted outcome) and assigning names to different diseases - is well understood. Broadly, considerable divergence in disease classification is allied with much fluidity in disease nomenclature. In this volume, where different cultural systems are explored and local epistemologies differentiated, we may appropriately pose the question: when and where is classification most prominent in extant Greek medicine? Perhaps the earliest nosological works provide the clearest instances. And these seem to be subject to influence from Cnidus. It is possible that these works betray non-Greek, Near Eastern sources: such systematisation may be more characteristic of another place and age. Certainly, from persistent variation, it is apparent that different Hippocratic authors put their own stamp on a large body of common inherited traditional material.

\section{Notes}

1 On all aspects of the Corpus, see Craik (2015).

2 On the character of Epidemics, see Deichgräber (1933/1971).

3 On such differences, see Jouanna (1974).

4 On the significance of malaria in Greek lands, see Craik (2017).

5 On terminology applied to different diseases, see Grmek (1989).

6 On the composition of the gynaecological works, see Grensemann (1975). 


\section{Select critical bibliography}

\section{Hippocratic Corpus: text}

Littré, E. (1839-61) Oeuvres complètes d'Hippocrate. Paris: J. B. Baillière.

Jones, W. H. S. (1923, 1931), Potter, P. (1988, 1995, 2010, 2012), Smith, W. D. (1994), Withington, E. T. (1928) Hippocrates. Edited and Translated. Henderson, J. (general editor). Loeb Classical Library. London/Cambridge, MA: Heinemann.

\section{Hippocratic Corpus: background and composition}

Craik, E. M. (2015) The 'Hippocratic' Corpus: Content and Context. London: Routledge. Jouanna, J. (1974) Pour une archéologie de l'école de Cnide. Paris: Les Belles Lettres.

Jouanna, J. (1999) Hippocrates. English Translation of French original, 1992. Baltimore: Johns Hopkins University Press.

Pormann, P. E. (ed.) (2018) The Cambridge Companion to Hippocrates. Cambridge: Cambridge University Press.

Smith, W. D. (1979) The Hippocratic Tradition. Ithaca, NY/London: Cornell University Press.

\section{Hippocratic Corpus: some components}

Deichgräber, K. (1971 [1933]) Die Epidemien und das Corpus Hippocraticum. Berlin: Akademie Verlag [reprinted, in an extended version, as Die Epidemien und das Corpus Hippocraticum mit Nachwort und Nachträgen. Berlin/New York: de Gruyter].

Grensemann, H. (1975) Knidische Medizin, Teil I. Ars Medica Abt. 2, Gr.-Lat. Med. Bd. 4. Berlin and New York: de Gruyter.

Grensemann, H. (1982) Die gynäkologischen Texte des Autors C nach den hippokratischen Schriften de Muliebribus I, II und de Sterilibus. Wiesbaden: Steiner.

Grensemann, H. (1987) Knidische Medizin, Teil II. Hermes Einzelschriften Heft 51. Stuttgart: Franz Steiner.

Jouanna, J. (1974) Hippocrate: Pour une archéologie de l'école de Cnide. Paris: Les Belles Lettres.

\section{Ancient Greece: disease and diseases}

Craik, E. M. (2017) 'Malaria and the Environment in Greece', in Cordovana, O. and Chiai, G. F. (eds.) Pollution and the Environment in Ancient Life and Thought. Stuttgart: Franz Steiner, 153-63.

Grmek, M. D. (1989) Diseases in the Ancient Greek World. Baltimore/London: Johns Hopkins University Press.

Lloyd, G. E. R. (2003) In the Grip of Disease. Oxford: Oxford University Press.

Nutton, V. (1983) 'The Seeds of Disease', Medical History 27, 1-34.

Rosenberg, C. E. (2003) 'What Is Disease?: In Memory of Oswei Temkin', Bulletin of the History of Medicine 77, 491-505. 